\title{
САЙМОН КУЗНЕЦ О ДЕМОГРАФИЧЕСКИХ ПРОБЛЕМАХ
}

\author{
АЛЕКСАНДР ТКАЧЕНКО 1,**
}

\begin{abstract}
В статье рассматриваются основные работь Саймона Кузнеца по вопросам взаимосвязи демографического и экономического роста. Отмечен особый вклад ученого в расширение показателей системы национальных счетов: включение ряда демографических показателей. Обращение американского экономиста к исследованиям народонаселения и его роли в экономической динамике в работе относится к более раннему периоду, чем это принято у ряда западных представителей истории экономической науки. Особое внимание уделено недостатку информации о нобелевском лауреате по экономике в России и незначительному числу переводов его фундаментальных работ на русский язык. Подчеркивается, что изучение творчества Кузнеца отечественными демографами поможет развитию фундаментальных экономико-демографических исследований в России.
\end{abstract}

Ключевые слова: экономическая динамика, демографические процессы, миграчия, распределение доходов, экономические ичикль, численность населения, семья, урбанизация, инновачии.

Нобелевский лауреат по экономике Саймон Кузнец - достаточно заметная в экономической науке фигура, однако его вклад в развитие мировой демографической мысли изучен не слишком хорошо - и не только в нашей стране. В изданной в русском переводе в 2008 г. книге М. Блауга «100 великих экономистов после Кейнса» отмечено, что Кузнец заинтересовался вопросами роста народонаселения в 1970-х годах [Блауг 2008: 132]. На самом деле это произошло намного раньше, о чем свидетельствует, в частности, решение поручить именно ему Обзорный доклад на Всемирной конференции ООН по народонаселению в 1965 г. в Белграде (этот доклад был частично переведен и опубликован на русском языке [Кузнец 1970]).

Статья посвящена исследованиям С. Кузнеца в области экономики и демографии, которые он рассматривал как тесно взаимосвязанные области общественного развития. Интерес к различным сторонам экономико-демографических взаимосвязей хорошо прослеживается в работах Кузнеца и его последователей, но в нашей стране заслуги Кузнеца на этом направлении исследований не очень известны и, по существу, не оценены. Да и сама личность исследователя остается в зоне, где больше белых пятен.

\footnotetext{
${ }^{1}$ ФИНАНСОВЫЙ УНИВЕРСИТЕТ ПРИ ПРАВИТЕЛЬСТВЕ РОССИЙСКОЙ ФЕДЕРАЦИИ (РОССИЯ).

*E-mail: alaltkachenko@gmail.com.

СТАТЬЯ ПОСТУПИЛА В РЕДАКЦИЮ В ФЕВРАЛЕ 2016 Г.

РАСШИРЕННАЯ ПЕЧАТНАЯ ВЕРСИЯ ДОКЛАДА, ПРЕДСТАВЛЕННОГО НА МЕЖДУНАРОДНОЙ КОНФЕРЕНЦИИ «ДЕМОГРАФИЧЕСКАЯ ТЕОРИЯ И ДЕМОГРАФИЧЕСКАЯ ИСТОРИЯ: ОТ ОПИСАНИЯ К ОБЪЯСНЕНИЮ», ПРОВОДИВШЕЙСЯ ИНСТИТУТОМ ДЕМОГРАФИИ НИУ «ВЫСШАЯ ШКОЛА ЭКОНОМИКИ» 22-23 ОКТЯБРЯ 2015 ГОДА.
} 


\section{ФИГУРА С. КУЗНЕЦА В ОТЕЧЕСТВЕННОЙ ЛИТЕРАТУРЕ}

Ошибки в информации об этой выдающейся фигуре экономической мысли и практики XX века встречаются во всех не слишком многочисленных отечественных изданиях (как и в зарубежных) и затрагивают самые разные стороны его биографии - от места рождения и учебы до периодизации его демографических исследований, прежде всего изучения закономерностей взаимосвязей экономического роста и роста численности населения. В энциклопедиях и даже в исследовательских статьях пишут о нем очень мало и с большими неточностями. В изданиях Международной ассоциации нобелевского движения (Россия), которая должна была бы пользоваться архивами Нобелевского фонда, встречается немало ошибок о месте рождения, учебы и т.д. Даже в биографической статье М. Абрамовица, написанной в память о С. Кузнеце, говорится о его учебе в Харьковском университете [Abramovitz 1986], что является ошибкой, быть может связанной с тем, что в Харьковском коммерческом институте (ХКИ), где он действительно учился, большинство преподавателей было из университета. Ту же ошибку повторяют Мэддисон [Maddison 2004: 7] и Карнацевич [Карнацевич 2005: 221].

Отметим, что С. Кузнец не оканчивал вуз в нашей стране. Он поступил в ХКИ, но на втором курсе его учебы начались преобразования учебных курсов и учебных заведений в Харькове, проводимые новой советской властью, поэтому он ушел работать в статистические органы. В сведениях о том, какую должность он занимал, тоже много неточностей. Кузнец не возглавлял статистический орган Украины, как ошибочно указывает ряд изданий, а работал только в самом Харькове ${ }^{1}$. Но даже за 2 года учебы в Коммерческом институте он все-таки смог получить блестящее образование по статистике, что признавали все, когда он приехал в США и сразу стал учиться на последнем курсе Колумбийского университета. По мнению Ангуса Мэддисона, «... когда С. Кузнец прибыл в США, он был уже искушённым и хорошо обученным экономистом с практическим опытом статистической работы» ${ }^{2}$ [Maddison 2004: 7-8].

Можно предположить, что признанный высокий уровень подготовки связан с преподавателями ХКИ, о которых подробно рассказано в работах В.М. Московкина [Московкин 2002; 2005; 2010]. Кафедру статистики в этом институте возглавлял знаменитый статистик Алексей Николаевич Анцыферов, выпускник Московского университета, который, как и многие именитые ученые, к несчастью для нас, покинул свое отечество, и дальнейшее его творчество проходило во Франции. Анциферов занимался и демографическими проблемами. Он опубликовал даже две специальных работы, прежде всего работу «Nemesis: Демографический этюд» в Записках Русского научного института в Белграде [Анцыферов 1938] ${ }^{3}$, где обосновывалась новая для того времени идея о замедлении в будущем прироста населения и даже возможной депопуляции из-за «коренного дефекта» его структуры.

\footnotetext{
${ }^{1}$ Хотя там и находилось в эти годы правительство советской Украины, но он работал в отделе статистики труда, относящемся к профсоюзам.

2 Это мнение приводит и В.М. Московкин в своей статье-комментарии к переводу Кузнеца [Московкин, Михайличенко 2012: 11].

${ }^{3}$ В некоторых источниках ошибочно датируется 1935 г.
} 
Когда автор этой статьи в 2015 г. выступал на конференции Института демографии НИУ ВШЭ, он пользовался библиоинформацией из официальных источников: данных Российской национальной библиотеки, энциклопедических справочников и словарей, но все они пропустили очень важное издание Института информации по общественным наукам (ИНИОН РАН), который еще в 1954 г. в своей серии «Новые книги за рубежом по общественным наукам» опубликовал первый реферат работы Кузнеца [Кузнец 1954], затем были переводы в этом же издании в 1956 г. и в 1972 г. - еще два реферата [Кузнец 1956; 1972], на что не забыла указать Л.Л. Васина [Нобелевские лауреаты XX века 2001: 45]. Национальная библиотека Республики Бурятия имеет наиболее полный список работ, включая крупные издания издательств «Статистика» [Кузнец 1973] и «Экономика» [Кузнец 1966], последняя работа приведена Кузнецом в списке «Мои основные публикации в области экономики», который завершает «нобелевскую» автобиографию. И при этом он очень мало цитируется как в экономических, так и демографических российских изданиях. Наше видение причин этого явления мы попытаемся изложить в данной статье.

Вначале необходимо отметить искажения даже в немногочисленных переводах работ С. Кузнеца последнего времени. В честь 250-летия МГУ им. М.В. Ломоносова вышел пятитомник «Мировая экономическая мысль. Сквозь призму веков», в 5 томе которого помещены лекции нобелевских лауреатов [Мировая экономическая мысль ... 2004]. Лекция С. Кузнеца изложена в переводе издания [Нобелевские лауреаты по экономике... 2003], который был неполным. Полный перевод всего текста лекции содержится в издании 2007 г. [Лауреаты Нобелевской премии ... 2007: 92-106]. При этом необходимо подчеркнуть, что оба перевода отличаются «осовремениванием» подлинного текста лауреата, которое в большинстве случаев нам представляется неоправданным. Приведем лишь один пример. Раздел 4 своей лекции Кузнец назвал «The Less Developed Countries» [Nobel Lectures ... 1992], что было не только оправдано, но отражало суть их положения в мировой экономике. Другой нобелевский лауреат Г. Мюрдаль открыто возражал против изменения термина со стороны ООН и превращения «слаборазвитых» стран в «развивающиеся». Синонимичным термином Мюрдаля страны «третьего мира» воспользовался автор перевода 2007 г., а автор перевода 2003 г. заменил на «развивающиеся страны». Представляется, что это искажение мысли автора лекции. Сам Кузнец в своих работах употреблял по отношению к странам третьего мира два определения: «underdeveloped» и «less developed» countries.

В определенной мере интерес к социальной области развития был заложен во время первой работы Кузнеца после защиты докторской диссертации в Колумбийском университете, когда он в течение полутора лет был научным сотрудником Совета по исследованиям в области социальных наук.

Национальная библиотека России имеет почему-то сведения только о работе [Кузнец 1921: 53-64], которая вышла в сборнике, подготовленном отделом статистики Южного бюро Всероссийского центрального совета профсоюзов. К первому и очень длительное время единственному в нашей стране переводу работ С. Кузнеца, имеющих отношение к демографии, принадлежит публикация в серийном издании «Новое в зарубежной демографии», за выпуск которого последующие поколения демографов должны благодарить А.Г. Волкова, наряду с первым директором НИИ ЦСУ СССР А.Я. Боярским, 15 лет заведовавшим кафедрой статистики на экономическом факультете МГУ, 
способствовавшим выходу этих выпусков. Боярский же написал предисловие к выпуску «Население и экономика» из этой серии, которое по тем временам было названо своеобразно - «Вводные замечания». В них он оговаривает, что авторы сборника опустили те части текста, в которых «суждения и толкования автора (Кузнеца) о характере взаимосвязи между экономическим ростом и тенденциями движения населения в СССР по меньшей мере недостаточно глубоки и не всегда вполне объективны» [Боярский 1970: 10], и добавляет: «Советский читатель отнесется критически к некоторым его суждениям». Но всё же читателю позволили самому судить о точности и верности суждений Кузнеца. Для тех времён это был смелый шаг. В сборнике удалось опубликовать выдержки из доклада Саймона Кузнеца ${ }^{4}$ на второй Всемирной конференции по народонаселению (Белград, 1965). С. Кузнец выступил и на следующей Всемирной конференции по народонаселению в Бухаресте (1975) с докладом о динамике населения и современном экономическом росте, который он характеризовал как «заметки к вопросу об исторической перспективе» [Kuznets 1975].

Когда же отечественные исследователи обратились к творчеству Кузнеца? Мы имеем очень мало работ в отечественной историографии и экономической мысли об этом лауреате. Впервые это произошло только в 100-летний юбилей со дня рождения Саймона Кузнеца в 2001 г. Есть всего 2 работы, появившиеся в год 100-летия со дня его рождения. Статья В.М. Московкина 5 о жизненном пути Кузнеца опубликована в украинском журнале «Университеты», а в Москве вышла статья И.В. Филатова [2001], который связал деятельность Кузнеца с проблемами модернизации постсоциалистических стран. В 2002 и 2003 гг. в украинских журналах также выходили статьи Московкина, который в дальнейшем за период между публикациями 2005 и 2010 г., значительно продвинулся на пути ликвидации белых пятен в биографии Кузнеца.

В 2003 г. вышел неполный перевод нобелевской речи [Нобелевские лауреаты по экономике... 2003], а в 2007 г. - полный ее перевод в трехтомнике о нобелевских лауреатах, который состоит из таких пазлов: краткая биография, которая написана самим лауреатом, его нобелевская лекция и краткий комментарий составителя. Впервые в 2007 г., когда вышел первый том, где даны сведения о лауреатах за 1969-1982 гг. (напомним, что Кузнец получил премию в 1971 г.), лекция была переведена на русский язык полностью, как и биография, которую пишут все лауреаты, но в ней Кузнец практически ничего не сказал об учебе и работе на своей родине, ограничившись более чем кратким упоминанием: «После двух лет учебы в России (г. Харьков) уехал в США» [Лауреаты Нобелевской премии ... 2007: 91].

В следующий раз о Саймоне Кузнеце напомнили несколькими статьями только к 110-летию со дня его рождения, когда, благодаря отдаленному преемнику ХКИ, Харьковскому национальному экономическому университету, была переведена на русский язык его магистерская работа [Московкин, Михайличенко 2012]. У нас иногда утверждают, что она была написана в Харькове на русском языке, но на самом деле это не так. Защищал её он всё-таки в Колумбийском университете, поэтому и работа была на английском языке

\footnotetext{
${ }^{4}$ Под статью (доклад) Кузнеца было отдано более 40\% всего объема издания, а остальные - четырем авторам.

${ }^{5}$ В 2011 г. позиционирован как профессор Белгородского госуниверситета.
} 
и посвящена Йозефу Шумпетеру. С другими работами, кроме вышеназванных переводов, наша научная среда должна знакомиться только в англоязычном варианте.

Этот реальный факт, который тоже относится к элементам забвения и объединяет в нашей отечественной истории экономических, демографических, статистических учений Саймона Кузнеца и два других великих имени XX века: Коррадо Джини и Джона Мейнарда Кейнса, чьи основные (в случае Джини) и до сих пор актуальные (в случае Кейнса) работы не переведены до сих пор.

Сам индекс Джини, который у нас в последнее десятилетие так любят и так часто используют в своих работах экономисты, как раз был апробирован и широко введен в экономическую жизнь как общепризнанный показатель благодаря работам Кузнеца.

В 1936 г. Кузнец принимал активное участие в учреждении Конференции по изучению доходов и благосостояния (Conference on research of income and wealth), имевшей задачей развитие системы национальных счетов в США, и сыгравшей роль в создании Международной ассоциации исследований по доходам и благосостоянию, его можно называть родоначальником современной системы национальных счетов ${ }^{6}$. На этой конференции Кузнец впервые выступил с изложением своих исследований по поводу расчёта ВВП и национального дохода по разработанной им методологии и методике. Тема распределения доходов населения - одна из главных в творчестве Кузнеца [Kuznets 1952; Kuznets 1953].

В завершение раздела об освещении фигуры и деятельности С. Кузнеца в нашей литературе, отметим, что нам представляется неплодотворным и даже сомнительным по отношению к памяти выдающегося учёного «возвращать» ему «отечественные» корни, меняя имя на Семён, как это предлагал В.М. Московкин [2010: 64] или как это делает в своих документах общественная организация «Ассоциация Нобелевского движения». И дело не только в том, что в мировую сокровищницу мысли он вошёл Саймоном С. Кузнецом, но и в его собственных решениях. Не стал же он менять фамилию на взятую отцом в США - Смит, а добавил её как второе имя. А эталоном для любых решений и «притязаний» должна быть его автобиография, которую собственноручно пишут все нобелевские лауреаты.

\section{САЙМОН КУЗНЕЦ О ВЗАИМОЗАВИСИМОСТИ ДЕМОГРАФИЧЕСКИХ И ӘКОНОМИЧЕСКИХ ПРОЦЕССОВ}

Первым «приобщением» С. Кузнеца к демографии была редко упоминаемая теперь работа о населении Филадельфии. Оценка населения Филадельфии и её пригородов, рабочей силы, занятости и прогноз на 1950 г. по этим показателям были выполнены Кузнецом и его ассистентами и опубликованы Пенсильванским университетом в 1946 г. [Kuznets et al. 1946]. По существу, эта первая работа Кузнеца о населении, но предметом нашего

\footnotetext{
${ }^{6}$ В литературе чаще звучит имя Р.Стоуна в связи с его участием в подготовке доклада ООН (1947) и как автора доклада «Упрощенная система национальных счетов» (1951), хотя Ю.Н. Иванов отмечает и заслуги С.Кузнеца [Иванов 2012:80].
} 
исследования является творчество ученого в области взаимосвязи демографических и экономических процессов - направлении, которое теперь называют экономической демографией (demographic economics) или экономикой народонаселения ${ }^{7}$. Прогноз населения, сделанный группой Кузнеца, базировался, прежде всего, на текущих наблюдениях 1940-1944 гг. Прогнозировались изменения общей численности населения, возрастной и половой структуры и изменения расового состава населения для периода 1940-1950 гг. на основе анализа данных за 1870-1940 гг. В отдельной части были опубликованы детальные таблицы этих прогнозов. Специальный раздел был посвящен применяемой методологии и основным допущениям, включая методы, используемые для оценки рождаемости, смертности, миграции за 1940-1950 гг. Работа выполнялась по заказу Филадельфийской городской комиссии планирования Исследовательского консультативного комитета по народонаселению и экономике. Разумеется, в этой работе Кузнец проявлял себя, прежде всего, как известный и искусный статистик, имеющий уникальный опыт анализа длинных динамических рядов. Работа вызвала несомненный интерес, о чем свидетельствует рецензия в «Population Index» [Formal demography ... 1947: 296].

Необходимо подчеркнуть отличие ученого от других представителей экономической и демографической науки: в своих работах Кузнец не только обогащал демоэкономические исследования, но и использовал собственно демографические методы в экономике, способствуя тем самым быстрому прогрессу в становлении её прогностических функций. Этот довольно необычный даже для наших дней феномен, когда экономисты используют демографические методы в своих работах. Как пишет его ученик Р. Фогель, Кузнец применил логистические кривые Р. Пирла, позволившие последнему выявить закономерности роста численности популяции, и актуарные таблицы Б. Гомперца с его идеей о росте смертности с увеличением возраста поколения [Демографическая энциклопедия 2013: 187, 573] для обсуждения проблемы пригодности этих и других математических функций для прогнозирования конкретных экономических процессов [Fogel 2001: 210] и альтернативных методов применения таких функций. Немногие экономисты той эпохи, подчеркивал Фогель, исследовали взаимосвязь между экономическим ростом и ростом населения в такой полной мере, как Кузнец. Методы Гомперца и Пирла Кузнец применил в фундаментальном труде, написанном в 1930 г. во время работы в Национальном бюро экономических исследований, в котором он исследовал вековые движения производства и цен и их влияние на циклические колебания на примере США, Великобритании, Бельгии, Германии и Франции [Kuznets 1930].

Автор биографической статьи о С. Кузнеце в энциклопедическом словаре Л.Л. Васина приводит такое высказывание Фогеля: «Его курс по экономическому росту включал историю технологических изменений на протяжении нового времени, демографию и теорию народонаселения...» [Нобелевские лауреаты ... 2001: 40]. Исследования Кузнеца по демографии и теории народонаселения в его экономических работах и являются предметом данной статьи.

\footnotetext{
${ }^{7}$ Мы рассматриваем эти понятия не как синонимичные, но близкие по существу и частично совпадающие. Подробнее см.: [Демографическая энциклопедия 2013: 925-927].
} 
Почему можно считать, что творчество С. Кузнеца продолжает оставаться для российских демографов, экономистов, социологов, представителей других направлений гуманитарных наук актуальным? Представляется, что исключительно важной для решения социально-демографических проблем и выбора направлений развития в XXI веке является мысль С. Кузнеца, что «современный экономический рост заставляет принимать меры по разрешению зарождающихся конфликтов, постоянно создаваемых изменениями в экономике и социальной структуре» [Лауреаты Нобелевской премии ... 2007: 98]. В этой мысли, как нам кажется, существенны два момента: (1) конфликты - это имманентная часть современного экономического и социального роста и (2) изменения в социальной структуре, где столь большую роль играют структуры демографические, столь же важны, как и экономические изменения, и имеют не меньшую силу воздействия на устойчивость экономического роста, которая является основной проблемой современной глобальной экономики. Этой позиции в современном мейнстриме придерживается большинство представителей экономической социологии и, хотелось бы надеяться, экономической демографии. Далее в нобелевской лекции Кузнец делает важный, и спустя 44 года многими экономистами не осмысленный, вывод: «Преемственность технологических инновационных характеристик современного экономического роста и социальных инноваций, облегчающих необходимую адаптацию, является наиболее важным фактором, влияющим на экономическую и социальную структуру» (выделено автором - А.Т.) [Лауреаты Нобелевской премии ... 2007: 98].

Среди 5 спецификаций, которые Кузнец считает необходимым рассмотреть при анализе распределения доходов в ходе экономического роста, первой он называет «количество членов семьи и их соотношение по уровню дохода», а к третьей относит «нахождение в определённом месте жизненного цикла данного члена семьи и соответственного дохода в зависимости от экономической активности» [Kuznets 1955: 1]. Анализируя этот сложный вопрос в такой особенной по составу населения стране, как США, необходимо и полезно, по его мнению, рассматривать долю в общем доходе таких специфических групп, как «резиденты» и «мигранты». Интересна также и его установка на классификацию временного анализа: предложение рассматривать статусно-доходные группы в достаточно длительном интервале (по поколениям или с интервалом в 25 лет). Обращаясь к менее очевидным группам факторов компенсационного кумулятивного эффекта концентрации сбережений, первым среди них Кузнец называет фактор демографический: в современных развитых странах имеются различные темпы роста (воспроизводства поколений - А.Т.) у богатых и бедных семей. Он предполагает, что даже без учёта миграции можно утверждать, что для самых богатых 5\% населения 1870 г. их потомки будут составлять в 1920 г. значительно меньший процент населения. Свои выводы он предлагает проверить на стране, где существует значительная иммиграция, - на США. Топ 5\% населения 1920 г. состоит только частично из топа 5\% 1870 г.: может быть, половина или даже большая часть должна происходить из группы с низкими доходами. Это означает, что период, в течение которого эффект влияния концентрации сбережений может быть определён, должен кумулятивно возрастать для любой зафиксированной ординарной группы, будь то верхние 1,5\% или 10\% населения, и не может быть больше, чем 50 лет. Поэтому анализ по поколениям или по признаку «резиденты-мигранты» так важен, ибо анализ просто по высоко- и низкодоходным группам теряет смысл при изучении 
долгосрочных изменений в долях и в неравенстве распределения [Kuznets 1955: 2]. Семью Кузнец вводит и в анализ возможных оценок национального дохода. Среди зависимостей этих оценок национального дохода он выделяет систему действующих общественных ценностей и природу семьи (выделено автором - А.Т.) [Kuznets 1953; 1968].

\section{ОСНОВНЫЕ ДОСТИЖЕНИЯ С. КУЗНЕЦА В ОБЛАСТИ ЭКОНОМИКО- ДЕМОГРАФИЧЕСКИХ ИССЛЕДОВАНИЙ}

Отличие творчества Кузнеца от многих других ученых состоит в «достижении-овладении» тремя большими вершинами, недосягаемыми, по нашему мнению, до сих пор не только для отдельных исследователей, но и целых коллективов. Первая состоит в том, что во всех работах Кузнеца прослеживается огромная ретроспектива: взаимосвязь экономического роста и демографических тенденций исследовалась по динамическому ряду данных с конца XVIII до середины XX века (в работах 1960-х годов) и далее (в других) - национального дохода с середины XVIII века. Он всегда для анализа берет десятилетия, столетия и исследует данные, оперируя такими длинными динамическими рядами. Об этом говорит в своей лекции и М. Мэддисон [Maddison 2004], который называет Кузнеца пионером в развитии количественной экономической истории. Количественный анализ длинных экономических рядов на несколько десятков или даже сотен лет является очень трудной задачей для исследователя, но именно такие ряды и их анализ хорошо сопрягаются с анализом демографических тенденций, значимые изменения которых происходят на протяжении длительного периода. Раздел «Квантифицирование и интерпретация мирового экономического роста» Мэддисон начинает с оценки научного творчества Кузнеца, который более чем кто-либо другой увеличил обратный горизонт от 1950 г. в исследовании развития «современного» экономического роста и интерпретации его движущих сил. Аналитические масштабы экономической истории, представленной с количественным фундаментом, оцениваются как революционные для экономической науки. Под современным ростом Кузнец понимает промышленную эпоху и называет 1760 г. как стартовую точку современного экономического роста [Kuznets 1961]. Но доступные в настоящее время данные, строго говоря, имеются только с периода около 1820-х годов. В 1930-1940-е годы Кузнец сделал, по выражению Мэддисона, массивный научный вклад в количественный анализ макроэкономической истории США (рост и структура ВВП, акционерный капитал, занятость, иммиграция, распределение доходов, внешняя торговля) [Maddison 2004: 10-11].

Вторая вершина творчества Кузнеца - это то, что он уже в то время (конец 1960-х начало 1970-х годов) был глобалистом, что явно выражено в его работах. Например, он предлагал «... стимулировать подобающее использование инноваций посредством генерирования общемирового знания» [Лауреаты Нобелевской премии ... 2007: 93]. Представляется, что здесь С. Кузнец по своим мыслям очень близок к идеям В.И. Вернадского, хотя в то время они еще не были опубликованы [Вернадский 1977]. Кузнец же ввел и термин «социальные инновации».

Третья вершина: Кузнец предстает как очень глубокий аналитик экономической истории. Именно он предложил рассматривать экономическое развитие по определенным 
эпохам и говорил, что развитие необходимо, особенно с инновационной точки зрения, анализировать всегда обязательно в рамках определённой экономической эпохи, которую вы выделяете, но никак не делать это перекрестным способом. Эти эпохи связаны с экономико-технологическими циклами, которые сам Кузнец называл длинными колебаниями (long swings) [Kuznets 1958], а другой известный экономист, нобелевский лауреат 1979 г. У.А. Льюис, назвал «циклами Кузнеца» [Abramovitz 1966: 520], каковыми они и вошли в историю экономической и, будем надеяться, демографической науки. Население не просто присутствует, а является составным образующим элементом в исследованиях Кузнецом широкой исторической перспективы процесса экономического роста, которые выявили ряд эмпирических закономерностей, прежде всего для Соединенных Штатов, а затем и для других стран. Например, были установлены длинные волны («циклы Кузнеца») темпов экономико-технологического роста некоторых стран как общие волны чередования быстрого и медленного роста технического прогресса, населения и национального дохода протяженностью 15-25 лет. Издание, которое приводит слова Абрамовица о Льюисе как авторе термина «циклы Кузнеца», отдает должное и роли демографических процессов в этих циклах: детальные исследования Кузнеца показали, что волны иммиграции и другие демографические факторы, такие как формирование домашних хозяйств, так же, как и изменения в возрастной структуре, брачности и уровне рождаемости, породили длительные колебания темпов экономического роста [Economics for the Modern ... 2009: 145]. Как специалист в области циклов М. Абрамовиц неоднократно обращался к этому аспекту творчества Кузнеца в своих работах [Abramovitz 1961; 1968]. В работах по теориям циклов («циклы Кузнеца») среди сфер экономической жизни Великобритании, США, других развитых стран он выделяет сферы, относящиеся к росту народонаселения, внешнюю и внутреннюю миграцию.

В свою очередь Льюиса объединяют с Кузнецом не только исследования влияния циклов на экономический рост и динамику населения, но и интерес к миграционным проблемам. В своей работе [Lewis 1954] он рассматривает гипотетические последствия возможной миграции из Индии и Китая, если бы она ничем не ограничивалась, а въезд в США был бы свободным для иммиграции из этих стран. «Массовая иммиграция, - по выражению Льюиса, - совсем другой коленкор (kettle of fish)». В случае такой миграции «уровень заработной платы в США, несомненно, будет снесен в сторону индийских и китайских уровней», а оплата труда иммигрантов окажется постоянной на уровне прожиточного минимума [Lewis 1954: 177]. В современной ситуации «миграционного кризиса» в Европе никто пока не поднимает вопроса о влиянии миллионов прибывших на уровень оплаты труда в европейских странах в недалеком будущем.

Не будем называть это четвертой вершиной, но нельзя не признать огромных заслуг Кузнеца в анализе взаимосвязанности демографического и экономического роста. Большее население по Кузнецу также способствует расширению масштабов экономики и росту отзывчивости к новым продуктам, потому что, уточняет он, меняется возрастная структура населения. Несмотря на эти позитивные аспекты высоких темпов роста населения, Кузнец признавал, как подчеркивает Р. Фогель, что резкое ускорение роста населения в наименее развитых странах, в основном происходящее благодаря быстрому снижению коэффициента 
смертности [Fogel 2001: 217-218] ${ }^{8}$, перегружает экономику и препятствует росту доходов на душу населения. Кузнец указал на экономическое значение того факта, что ускорение роста населения было обусловлено, в первую очередь, снижением уровня смертности, а это, в свою очередь, связано со снижением показателей заболеваемости, что способствует повышению производительности труда. Взаимосвязанные снижение уровня заболеваемости и рост производительности труда, повышают отдачу инвестиций как в рост уровня образования детей, так и в улучшение качества жизни. К тому же более быстрое снижение уровня смертности в городах, чем в сельских районах, способствует урбанизации и ускоряет индустриализацию. Тенденция снижения смертности, стимулирующая снижение рождаемости и содействующая миграции, также способствовала экономическому росту путем адаптации социальных институтов к новым экономическим возможностям. Снижение размера семей с завершенным репродуктивным циклом и тот факт, что это происходило с различной скоростью в сельских и городских районах, привело к ослаблению влияния семьи на молодые генерации и сделало их открытыми современной этике, что продвигало их участие в быстро меняющейся экономической системе. Он рассматривал этот разрыв между кровными узами и экономическими выгодами как центральный фактор победы объективных результатов экономической деятельности над более традиционными приоритетами семейных связей.

Исследования Кузнеца по синергизму экономических и демографических изменений были настолько многогранны, что не поддаются краткому изложению, как писал Фогель в Memoir [Fogel 2001: 218]. Поэтому Фогель выбирает для комментариев только одну линию исследований Кузнеца: воздействия демографических факторов на измерения неравенства в распределении доходов. Кузнец стал углубляться в проблемы измерения степени неравенства в распределении доходов и определения факторов, которые начинают способствовать этому неравенству в начале своей карьеры. Поэтому и нельзя согласиться с мнением М. Блауга, касающимся периодизации творческого интереса Кузнеца к демографическим процессам: он проявился значительно раньше, чем полагает Блауг, еще до выступления на Всемирной конференции по народонаселению 1965 г. Особое место в творчестве Кузнеца занимает экономика национальных меньшинств, которой и в новом веке уделяется, по нашему мнению, слишком мало концептуального и эмпирического внимания.

Последняя изданная при жизни книга Р. Фогеля о его учителе С. Кузнеце [Fogel 2013] вышла в апреле (а он ушел из жизни в июне 2013 г.) и была написана коллективом авторов, в который также вошли жена Фогеля Инид и два сотрудника Национального бюро экономических исследований, они же сотрудники Центра экономики народонаселения Высшей школы бизнеса Чикагского университета ${ }^{9}$. Книга в основном посвящена деятельности Бюро (NBER), в котором вместе Кузнец и Фогель не работали ${ }^{10}$ (последний по свидетельству Р. Истерлина получил от Кузнеца импульс к демографическим исследованиям), и успехам Бюро в создании концепции валового внутреннего продукта,

\footnotetext{
${ }^{8}$ В своей статье по случаю 100 -летия со дня рождения С. Кузнеца Р. Фогель выделяет раздел «Роль роста населения».

${ }^{9}$ Nathaniel Grotte - помощник директора Центра экономики народонаселения.

${ }^{10}$ Р. Фогель начал свою работу в Бюро в 1978 г., С. Кузнец покинул Бюро в 1961 г.
} 
которая дала возможность впервые в мире определить эффективность экономики в целом. Собственно, научным методам С. Кузнеца, в том числе в области экономикодемографических связей, посвящена только пятая глава книги «Научные методы Саймона Кузнеца», в которой лишь частично и очень бегло затронуты интересующие нас вопросы, а их освещение в основном повторяет мысли и идеи Фогеля, изложенные в 2001 г. в упомянутой статье [Fogel 2001]. Главная идея книги 2013 г. подчеркивает тот факт, что исследования Кузнеца и его соратников создали из экономических исследований такую научную дисциплину, знания которой могут найти важное практическое применение.

\section{ТЕОРИЯ ЭКОНОМИЧЕСКОГО РОСТА И ДЕМОГРАФИЧЕСКОЕ РАЗВИТИЕ: ВЗАИМОСВЯЗИ И АВТОНОМНОСТЬ}

Исследователи Центра изучения народонаселения Пенсильванского университета в 1950 1960-е годы подготовили большое экономико-демографическое исследование, изданное в трех томах, об экономическом росте и перераспределении населения США по территории страны в период 1870-1950 гг. В первом томе (1957) анализировалась основная статистическая информация, составившая базу исследования; во втором томе (1960) перераспределение экономической активности. Третий том (1964) состоял из 2 частей: в первой Хоуп Элдридж (англ. Норе T. Eldridge) дал оценку международной миграции в США и провел системный демографический анализ, во второй части известнейший американский социолог Дороти Суэйн Томас (англ. Dorothy Swaine Thomas) ${ }^{11}$ уделила специальное внимание количественным результатам изучения взаимосвязей между экономическим развитием и перераспределением населения по территории США. По двум основным компонентам (дифференциации естественного прироста по регионам и роста, приходящегося на нетто-миграцию) была показана важность перераспределении населения по штатам для экономического развития страны. Обстоятельное предисловие к третьему обобщающему тому написал С. Кузнец. Книги вышли под эгидой Американского философского общества. Наибольший интерес, по мнению журнала «The Journal of Economic History» [Reviews of Books 1965: 436], вызывает пятая часть 3 тома «Потоки миграции», в которой Элдридж, используя данные о штате рождения и штате местожительства (residence), показывает преобладающие потоки общей миграции (gross migration) и роль миграции из-за рубежа.

Теория экономического роста, по Кузнецу, должна строиться на обширном фактическом материале и эмпирических исследованиях, охватывающих 4 ключевых момента: демографический рост, рост знаний, адаптацию национальных экономик к факторам роста и внешнеэкономические отношения. Поэтому считается, что путь Кузнеца к созданию единой общей теории экономического роста «вылился в ряд исторических и статистических исследований роста населения и национального продукта» [Kuznets 1946; 1952].

\footnotetext{
${ }^{11}$ Первая женщина - президент Американской социологической ассоциации. 
Среди выделяемых им аспектов экономической жизни, когда по мере роста ВВП происходит глубокое преобразование экономической структуры стран, отметим структуру занятости (отраслевую и профессиональную), распределение занятий на работу внутри семьи и на рынке, численность, возрастной состав и территориальное распределение населения, а также межстрановые потоки рабочей силы. Из этих крупнейших проблем общественной жизни XX века в XXI веке остаются всё еще нерешенными вопросы включения стоимостной оценки ряда занятий внутри семьи в ВВП (методология расчета в рамках системы национальных счетов - СНС) для обоснованности включения, например, нефинансовых, нематериальных затрат на воспитание детей и выполнения ряда семейных обязанностей) и характер баланса трудовой миграции населения для принимающих экономических мигрантов стран.

Далее необходимо обратиться еще к такой идее Кузнеца, которую, к сожалению, не развивают отечественные ученые, как двойственное влияние урбанизации. Он был урбанистом - сторонником современного образа жизни: «Нет современной технологии, совместимой со стереотипом сельского образа жизни, большими семьями и поклонением перед нетронутой природой» [Лауреаты Нобелевской премии . . . 2007: 93]. Представляется, что это ответ через 40 лет современным адептам такого понимания «зелёной» экономики, которое требует остановить технический прогресс и экономический рост ради гармонии с окружающей средой. У Кузнеца немало работ по миграции с огромной ретроспективой, например, он анализировал динамику миграции за 75 лет до Первой мировой войны, специально подчеркивая, что включает Российскую империю с ее азиатской частью, - это ещё раз свидетельствует о фундаментальной статистической основе всех его теоретических работ. Он отмечает значительные издержки, связанные с миграцией из сельскохозяйственных районов в города, говорит о высоких затратах как для самих индивидов, так и для общества в целом. Подобные исследования до сих пор большая редкость для экономистов, социологов, демографов. Кузнец отмечает обострение национализма как дорогостоящее последствие функций государства, что особенно актуально звучит на фоне дискуссий последних лет о провале или даже вредности для западного общества концепции и политики мультикультурализма.

Еще в начале 1960-х годов, за много десятилетий до современной российской экономической мысли, когда мы стали много говорить об инновациях и инновационном развитии, энциклопедичность Саймона Кузнеца позволяла ему заложить фундамент для современных исследований. Он выделял инновации социальные, юридические, в социальных структурах, в познании и даже в идеологии. Широкая научная общественность до сих пор не знакома с развернутыми идеями Кузнеца на эту тему. И ещё эвристична мысль Кузнеца о том, что, хотя любая научная проблема лишь временна, от проблем мы никогда не избавимся, какого бы уровня экономического развития не достигли. И уже исторически короткий период XXI века демонстрирует это нам со всей наглядностью в самых высокоразвитых странах.

Когда Кузнец исследует демографические процессы, он часто обращается к идее, что прямая связь между ростом ВВП и ростом доходов населения напрямую отсутствует и что существуют периоды развития каждого государства, когда эти 2 ряда между собой не связаны, и это отсутствие связи не зависит от достигнутого уровня развития. Как идеолог 
современной системы национальных счетов он предсказывал, что усилия по расширению рамок национального балансирования приведут к выявлению не измеряемых пока таких положительных результатов, как улучшение здоровья и рост продолжительности жизни, большая мобильность, уменьшение неравенства в доходах населения. И поэтому, хотя Кузнец много работ посвятил полностью или частично демографическим проблемам и вопросам человеческого капитала, его самой большой научно-практической заслугой можно считать включение в счета NIPA (National income and product accounts) ${ }^{12}$ показателей улучшения здоровья и увеличения продолжительности жсизи. Сравнения этого исторического по значению факта с советской методологией расчета национального дохода по «признаку» так называемого материального производства достаточно, чтобы понять различие фонов демографических исследований западной и отечественной научной мысли 1960-1970-х годов.

Несомненен большой вклад С. Кузнеца в изучение развития «третьего мира» - эти страны он называл, как и Г. Мюрдаль, слаборазвитыми странами. Кузнец отмечает очень интересный демографический факт, причины которого так и остались до конца не изученными до сих пор: «ни одна из ныне развитых стран не сталкивалась с таким высоким уровнем естественного прироста, который характерен для многих стран третьего мира на протяжении двух-трех последних десятилетий» [Лауреаты Нобелевской премии ... 2007: 101], т.е. в 1960-70-е годы Кузнец говорил, что вклад в уменьшение смертности в развитых европейских странах не связан с общим развитием этих стран, с промышленной революцией и с ростом доходов на душу населения; в первую очередь это связано с инновациями в здравоохранение. Именно они привели к снижению смертности и увеличению продолжительности жизни. К этой же мысли пришли в конце XX века другие ученые, в том числе это прозвучало на Всемирной конференции по народонаселению и развитию 1994 г. (Каир).

Первые работы на эту тему у С. Кузнеца были еще до Второй мировой войны. Наиболее крупная работа, посвященная демографическим проблемам, кроме доклада на Всемирной конференции по народонаселению в Белграде, - «Шесть лекций по экономическому росту» [Kuznets 1959]. По этой и многим аналогичным причинам нельзя относить «интерес» Кузнеца к исследованию проблем народонаселения к 1970-м годам.

Необходимо также отметить следующее. Во-первых, Кузнец написал работу [Kuznets 1965], в которой подчеркнул, что наиболее важны вложения в человеческое развитие и что это - наиболее важный капитал среди других факторов производства. Если взять первую работу одного из создателей теории человеческого капитала Теодора Шульца [Schultz 1961] (работа Гэрри Беккера вышла даже позже), можно увидеть, что Кузнец мыслил в том же русле и видел определяющее будущее именно этого фактора производства. Но до сих пор в отечественной литературе об инвестициях и инновациях доминирует технократический подход, а человеческий капитал даже не упоминается. Отмечая быстрые структурные сдвиги при высоком темпе общего роста в эпоху индустриализации, Кузнец выделяет изменение значения международных потоков товаров, фондов и людей и

${ }^{12}$ C 1993 г. - Система национальных счетов. Последняя версия: [System of National ... 2009]. 
изменение экономических категорий в пределах этих движений через национальные границы. Высокий темп структурных сдвигов, который в анализе он отделяет от высоких темпов роста продукта на душу населения, в свою очередь вызывает сдвиг от одной производственной и социальной части к другой, но не влияет на все части одновременно. От современного экономического роста неотделима способность индивидуумов и общественных институтов реагировать на непрерывные и быстрые изменения в потенциале экономического роста. А все эти изменения взаимосвязаны со взглядами, «которые воздействуют на нормы демографического поведения». Поражает своей современностью и такая мысль С. Кузнеца, высказанная 50 лет назад: «Взаимосвязь между демографическими тенденциями и экономическим ростом важна не только вследствие изменений в численности населения..., но также вследствие изменений в качестве людей и в экономически значимых нормах их поведения» [Кузнец 1973: 110].

В 1956-1963 годах Кузнец опубликовал в одном и том же журнале «Economic Development and Cultural Change» 8 объемных статей под общим названием «Количественные аспекты экономического роста наций», начав с темы экономического развития и культурных изменений. Эти важнейшие работы тоже до сих пор не переведены на русский язык. Кузнец говорил о влиянии экономического роста (увеличение ВВП на душу населения) на динамику смертности и пришел к выводу, что закономерность снижения смертности с ростом ВВП не имеет силы для отдельных стран и, «что более важно, во времени». Он имел в виду постоянную и прочную связь [Kuznets 1963]. И эти пионерные для того времени мысли Кузнеца с успехом впоследствии были развиты А. Сеном, получившим за них нобелевскую премию. Гораздо большее влияние оказывают, по мнению Кузнеца, технические нововведения в здравоохранении в XX веке или урбанизация в XIX веке.

Выпускник Пенсильванского университета, в котором Кузнец проработал почти 20 лет, Ричард Истерлин написал о нём биографические статьи в трех энциклопедиях [Encyclopedia of Population 2003; The New Palgrave 1987; The International Encyclopedia ...1979], хотя интересен нам прежде всего тем, что в 2009 году получил престижную премию Института экономики труда (Institute for the Study of Labor, Bonn) за вклад в анализ субъективного благополучия и за исследования взаимосвязи демографического развития и экономических результатов. Интересу к экономико-демографическим проблемам Истерлин обязан именно Кузнецу, его интеллектуальному влиянию во время совместной работы в Бюро экономических исследований (1956-1961). В определенной мере Истерлина можно считать и продолжателем вслед за Абрамовицем исследований проблемы взаимовлияния длинных колебаний (long swings) в численности населения и экономического роста [Abramovitz 1961; Easterlin 1968; 2000]. В отечественной литературе Истерлина цитируют в связи с политикой налогообложения, направленной на перераспределение капиталов (сбережений) между молодыми и пожилыми иждивенцами для покрытия растущих общественных затрат на содержание пожилых иждивенцев. Признается, что «проблема политической приемлемости такой меры достаточно серьезна, но она не кажется неразрешимой» [Демографическая модернизация ... 2006: 524]. Этот вывод Истерлина нам представляется весьма уязвимым и не учитывающим признанных выводов теории человеческого капитала. 
Можно подчеркнуть очень важную мысль ученого, которая близка к проблемам нашей страны даже в XXI веке. Это различие демографических показателей между городским и сельским населением. Конечно, Кузнец был не первым, кто это отметил. Отдельные представители науки тоже об этом писали, но он это говорил аргументировано и раньше многих других. При этом цитировал работу Кейнса 1937 г. «О некоторых экономических последствиях сокращения численности населения». Это различие между сельским и городским населением, о котором говорил Кузнец и которое, как он подчеркивал, даже в ходе уменьшения коэффициентов, остается значительным, сохраняется в России и в развивающихся странах, например входящих в БРИКС, до сих пор.

\section{КРАТКИЕ ВЫВОДЫ}

Является ли риторическим вопрос: почему же экономисты так много занимаются демографическими проблемами и виден ли их вклад в демографию? Или необходимы особые доказательства плодотворных связей демографии и экономической науки? Творческое наследие С. Кузнеца и других названных в статье экономистов отвечает на этот вопрос: потому что без человеческого фактора и соответственно воспроизводящих его процессов, без человеческого капитала невозможно строить модели и отслеживать феномен экономического развития. Если обратиться к Первой Всемирной конференции по народонаселению, которая проходила в 1927 г. в Женеве, то там самую крупную группу мировых имён составили экономисты: Дж. М. Кейнс, К. Джини, Р. Кучинский и другие.

Саймон Кузнец много работ посвятил полностью или частично демографическим проблемам и вопросам человеческого капитала, его самой большой научно-практической заслугой можно считать включение в национальные счета показателей улучшения здоровья и увеличения продолжительности жизни населения.

До сих пор в отечественной литературе об инвестициях и инновациях доминирует технократический подход и игнорируется роль человеческого капитала потому, что нет такой связки работ демографов и экономистов, которая наблюдалась при Кузнеце в исследованиях Бюро экономического анализа и в Принстонском университете. Важный вывод из анализа экономико-демографических работ Кузнеца и его учеников состоит в том, что оценки, измерения и прогнозы исследователей теперь имеют решающее значение для принятия решений правительств; можно предположить, что современная экономическая и демографическая ситуация в самой России и её положение в глобальной экономике приведут к такому же последствию, рекомендации научного сообщества будут тоже иметь решающее значение при выборе решений федеральных и региональных органов власти.

По-видимому, вехой начала исследовательского направления по изучению творчества С. Кузнеца в отечественной науке и влияния на это творчество его жизненного 
пути можно считать период после его 100-летнего юбилея $(2001)^{13}$. В Киеве, также в юбилей ученого, но уже следующий (2011), был проведен международный симпозиум, посвящённый Саймону Кузнецу, и в 2012 г. создана научная общественная организация «Международный институт развития и самоорганизации им. Саймона Кузнеца». Активный участник этих событий - российский экономист Ю.В. Яковец [2011], один из «новых открывателей» Н.Д. Кондратьева (с последним Кузнец вел переписку, когда Кондратьев уже был в заключении). Таким образом, еще большая «волна» интереса относится к 2010 - м годам, и, будем надеяться, она не прервется до следующего юбилея, а изучение творчества Саймона Кузнеца, в котором чрезвычайно ценным мы считаем исследования взаимосвязи демографических и экономических процессов, включающее и переводы его известных в мировой научной мысли работ на русский язык, станет важной составной частью отечественных исследований в области демографической теории и экономической демографии.

\section{ЛИТЕРАТУРА}

Аникин А.В. (1995). Люди науки: встречи с выдающимися экономистами. М.: «Дело Лтд».

Анцыферов А.Н. (1938). Nemesis: демографический этюд // Записки Русского научного института в Белграде. Вып.15. Белград.

Блауг М. (2008). 100 великих экономистов после Кейнса / Пер. с англ.; под ред. М.А. Сторчевого. СПб.: Экономическая школа.

Боярский А.Я. (1970). Вводные замечания // Население и экономика. Новое в зарубежной демографии. Сб.3 / Под ред. А.Г. Волкова, А.Я. Кваши. М.: Статистика.

Вернадский В.И. (1977). Размышления натуралиста. Книга 2. Научная мысль как планетное явление. М.: Наука.

Демографическая модернизация России, 1900-2000 (2006) / Под ред. А.Г. Вишневского. М.: Новое издательство.

Демографическая энциклопедия / Редкол.: А.А. Ткаченко, А.В. Аношкин, М.Б. Денисенко и др. М.: Издательство «Энциклопедия».

Иванов Ю.Н. (2012). История возникновения международной и отечественной статистики // Вопросы статистики. №8.

Карнацевич В. (2005). 100 знаменитых харьковчан. Харьков: ФОЛИО.

Кузнец С. (1921). Денежная заработная плата рабочих и служащих фабрично-заводской промышленности г. Харькова в 1920 году // Материалы по статистике труда на Украине / Под ред. И.Н. Дубинской. Вып. 2. Харьков.

(1954). Доля лиц с высоким доходом в национальном доходе и сбережениях // Новые книги за рубежом по общественным наукам. №2. М.

13 Исключение составляет книга А.В. Аникина [1995], одного из моих профессоров на экономическом факультете МГУ им. М.В. Ломоносова, - краткие мемуары о его встречах с великими экономистами, не рассматривающая труды этих ученых. 
(1956). Экономическое развитие Бразилии, Индии, Японии // Новые книги за рубежом по общественным наукам. №13. М.

(1966). Современный экономический рост: норма, структура и протяженность. М.: Экономика.

(1970). Демографические аспекты современного экономического роста // Население и экономика. Новое в зарубежной демографии. Сб.3 / Под ред. А.Г. Волкова, А.Я. Кваши. М.: Статистика: 103-166.

(1972). Экономический рост наций. Совокупный продукт и структура производства // Новые книги за рубежом по общественным наукам. №7. М.

(1973). Население, капитал и рост. Сборник очерков. М.: Статистика.

Лауреаты Нобелевской премии по экономике: в 3 т. (2007) / Науч. ред. В.В. Окрепилов. Т.1: 1969-1982. СПб.: Наука.

Мировая экономическая мысль. Сквозь призму веков. В 5 т. (2004) // Всемирное признание: лекции нобелевских лауреатов. T.V в 2 кн. Кн.1 / Отв. ред. Г.Г. Фетисов. М.: Мысль.

Московкин В.М. (2002). Семён Кузнец: его профессиональное окружение в Харькове и первая научная работа // Бизнес Информ. №9-10.

----------- (2005). Семён Кузнец: жизнедеятельность и его вклад в мировую науку // Проблеми науки, освіти та управління. Збірник наукових праць. Вып.VII.

(2010). Неизвестный Семён Кузнец: учеба в Харькове // Universitates: наука и просвещение. №1.

Московкин В.М., Д. Ю. Михайличенко (2012). Вступление. Саймон Кузнец и Харьковская высшая экономическая школа начала XX ст. // Кузнец С. Экономическая система д-ра Шумпетера, излагаемая и критикуемая; Перлман М. Две фазы заинтересованности Кузнеца Шумпетером / Сост. В. М. Московкин, Д. Ю. Михайличенко, перев. Е.Е. Перчик; под ред. В.С. Пономаренко. Харьков: ИД «ИНЖЕК».

Нобелевские лауреаты XX века. Экономика (2001). Энциклопедический словарь. М.: РОССПЭН.

Нобелевские лауреаты по экономике: взгляд из России (2003) / Под ред. Ю.В. Яковца. М.: «Гуманистика».

Филатов И.В. (2001). Теоретическое наследие С. Кузнеца и проблемы модернизации постсоциалистических стран // Социально-экономическая трансформация в России / Под ред. Е.А. Киселёвой. М.: МОНФ: 77-98.

Яковец Ю.В. (2011). Научное наследие Саймона Кузнеца: синтез теорий циклов, эпохальных инноваций и экономического роста: к 110-летию со дня рождения нобелевского лауреата по экономике Саймона Кузнеца. М.: МИСК.

Abramovitz M. (1961). The nature and significance of Kuznets cycles // Economic development and cultural change. Vol.9. №3. Essays in the quantitative study of economic growth, presented to Simon Kuznets on the occasion of his sixtieth birthday, University of Chicago Press, by His Students and Friends (April1961): 225-248.

(1966). Readings in business cycles selected by a committee of the American economic association. London: George Allen\&Unwin Ltd. 
(1968). The passing of the Kuznets cycle // Economica. New series. Vol.35. №140: 349-367.

(1986). Simon Kuznets (1901-1985) // The journal of economic history. Vol.46. №1.

Easterlin R.A. (1968). Population, labor force, and long swings in economic growth: the American experience. New York: Columbia University Press.

(2000). Twentieth-century American population growth // The Cambridge economic history of the United States. Vol.3. The twentieth century. S.L. Engerman, R.E. Gallman, eds. Cambridge University Press.

Economics for the modern built environment (2009) / L. Ruddock, ed. London and New York: Taylor \& Francis.

Fogel R.W. (2001). Simon S. Kuznets 1901-1985. A biographical memoir // Biographical memoirs. Vol.79. The National Academy Press. Washington: Hoselitz Bert F.: 433-454.

Fogel R.W, E.M. Fogel, M. Guglielmo, N. Grotte (2013). Political arithmetic: Simon Kuznets and the empirical tradition in economics. Chicago: University of Chicago press.

Formal demography: United States, 1722. (1947) // Population index. Vol.13. №4: 292-305.

Kuznets Simon S. (1930). Secular Movements in Production and Prices: Their Nature and Their Bearing upon Cyclical Fluctuations. Boston and New York.

(1946). National products since 1869. N.Y.

(1952). Long-term changes in the national income of the United States of America since 1890 // Income and wealth of the United States: Trends and structure. Income and wealth series. Vol.2. Cambridge.

(1953). International differences in income levels: reflection on their causes // Economic change. New York.

(1955). Economic growth and income inequality // The American economic review. Vol.XLV. №1.

(1958). Long swings in the growth of population and in related economic variables // Proceedings of the American philosophical society. Vol.102. №1: 25-52.

(1959). Six lectures on economic growth. Glencoe, Illinois: Free Press.

(1961). Capital in the American economy: its formation and financing. Princeton.

(1963). Quantitative aspects of the economic growth of nations: VIII. Distribution of income by size // Economic development and cultural change. Vol.11. №2. Part 2: 1-80. Kuznets S. (1965). Economic growth and structure: selected essays. N.Y.

(1968). Developed and underdeveloped countries: some problems of comparative analysis // Zeitschrift für die gesamte Staatswissenschaft. Bd. 124.

(1974). Demographic aspects of the distribution of income among families: recent trends in the United States / Econometrics and economic theory: Essays in honor of Jan Tinbergen. W. Sellekaerts, ed. London.

(1975). Population trends and modern economic growth: notes towards a historical perspective. Population debate: dimensions and perspectives. Papers of the World population conference. Bucharest, 1975. Vol. 1 // Population Studies. №57.

Kuznets S.S., E.D. Burdick, E.P. Hutchinson, D.T. Rowlands (1946). Population of Philadelphia and environs in 1950. Philadelphia: University of Pennsylvania Press. 
Lewis W.A. (1954). Economic development with unlimited supplies of labor // The Manchester school. Vol.22. Issue 2: 139-191.

Maddison A. (2004). Contours of the world economy and the art of macro-measurement 1500$2001 / /$ Ruggles lecture, IARIW $28^{\text {th }}$ General conference. August 2004. Cork, Ireland. P. 68.

Nobel lectures. Economics 1969-1980 (1992) / A. Lindbeck, ed. Singapore: World scientific publishing Co.

Reviews of books (1965) // The Journal of Economic History. Vol.25. Issue 03 (Sept).

Schultz T.W. (1961). Investment in human capital // American Economic Review. Vol.52. №1: $1-17$.

System of National Accounts 2008 (2009). European Commission, International Monetary Fund, Organization for Economic Co-operation and Development, United Nations, World Bank. 


\section{SIMON KUZNETS ON DEMOGRAPHIC ISSUES}

\section{ALEXANDER TKACHENKO ${ }^{1, *}$}

The article discusses the main works of Simon Kuznets analyzing the relationship between demographic and economic growth. The article notes the special contribution of the scientist to the expansion of the System of National Accounts by the inclusion of a number of demographic indicators. Kuznets' research in the field of population science and of the role of the population in economic dynamics goes back much further than is accepted by a number of Western scholars of economics. Particular attention is paid to the lack of information in Russia about the Nobel Laureate in Economics and to the paucity of translations of his fundamental works into Russian. The author concludes that Russian demographers studying the work of this scientist can promote the development of fundamental demo-economic research in Russia.

Key words: economic dynamics, demographic processes, migration, income distribution, economic cycles, population, family, urbanization, innovations.

\section{REFERENCES}

Abramovitz M. (1961). The nature and significance of Kuznets cycles // Economic development and cultural change. Vol.9. №3. Essays in the quantitative study of economic growth, presented to Simon Kuznets on the occasion of his sixtieth birthday, University of Chicago Press, by His Students and Friends (April1961): 225-248.

(1966). Readings in business cycles selected by a committee of the American economic association. London: George Allen\&Unwin Ltd.

(1968). The passing of the Kuznets cycle // Economica. New series. Vol.35.

№140: 349-367.

(1986). Simon Kuznets (1901-1985) // The journal of economic history. Vol.46.

№1.

Ancyferov A.N. (1938). Nemesis: demograficheskij etyud [Nemesis: demographic etude] // Zapiski Russkogo nauchnogo instituta v Belgrade. Vyp.15 [Study papers of the Russian scientific institute in Belgrade. Iss.15]. Belgrad.

Anikin A.V. (1995). Lyudi nauki: vstrechi s vydayushhimisya ekonomistami [Men of science: meeting with prominent economists]. Moscow: "Delo Ltd".

Blaug M. (2008). 100 velikix ekonomistov posle Kejnsa [One hundred great economist since Keynes]. St. Petersburg: Ekonomicheskaya shkola.

Boyarsky A.Ya. (1970). Vvodnye zamechaniya [Introductory remarks] // Naselenie i ekonomika. Novoe v zarubezhnoj demografii. Sb.3 [Population and economy. New in foreign demography. Vol.3] / A.G. Volkov, A.Ya. Kvascha, eds. Moscow: Statistika.

Demograficheskaya enciklopediya [Demographic encyclopedia] (2013) A.A. Tkachenko, A.V. Anoshkin, M.B. Denisenko, etc., eds. Moscow: Izdatel'stvo "Enciklopediya".

Demograficheskaya modernizaciya Rossii, 1900-2000 [Demographic modernization of Russia, 1900-2000] (2006) / A.G. Vishnevsky, ed. Moscow: Novoe izdatel'stvo.

\footnotetext{
${ }^{1}$ Financial University Under the Government of the Russian FEDERATION (Russia).

*CORRESPONDENCE: alaltkachenko@gmail.com.

DATE RECEIVED:: FEBRUARY 2016.
} 
Easterlin R.A. (1968). Population, labor force, and long swings in economic growth: the American experience. New York: Columbia University Press.

(2000). Twentieth-century American population growth // The Cambridge economic history of the United States. Vol.3. The twentieth century. S.L. Engerman, R.E. Gallman, eds. Cambridge University Press.

Economics for the modern built environment (2009) / L. Ruddock, ed. London and New York: Taylor \& Francis.

Filatov I.V. (2001). Teoreticheskoe nasledie S. Kuznetsa i problemy modernizacii postsocialisticheskix stran [The theoretical legacy of Simon Kuznets and problems in transition countries modernization] // Social'no-ekonomicheskaya transformaciya v Rossii [Social-economic transformation in Russia] / E.A. Kisselyeva, ed.. Moscow: MONF: 77-98.

Fogel R.W. (2001). Simon S. Kuznets 1901-1985. A biographical memoir // Biographical memoirs. Vol.79. The National Academy Press. Washington: Hoselitz Bert F.: 433-454.

Fogel R.W, E.M. Fogel, M. Guglielmo, N. Grotte (2013). Political arithmetic: Simon Kuznets and the empirical tradition in economics. Chicago: University of Chicago press.

Formal demography: United States, 1722. (1947) // Population index. Vol.13. №4: 292-305.

Ivanov Yu.N. (2012). Istoriya vozniknoveniya mezhdunarodnoj i otechestvennoj statistiki

[History of creation of the international and national statistics] // Voprosy statistiki [Statistical issues]. №8.

Jakovets Y.V. (2011). Nauchnoe nasledie Sajmona Kuznetsa: sintez teorij ciklov, epoxal'nyx innovacij i ekonomicheskogo rosta: k 110-letiyu so dnya rozhdeniya nobelevskogo laureata po ekonomike Sajmona Kuznetsa [The scientific legacy of Simon Kuznets: synthesis cycles theories epoch-making innovation and economic growth: the $110^{\text {th }}$ anniversary of the Nobel laureate in economics Simon Kuznets]. Moscow: MISK.

Karnacevich V.I. (2005). 100 znamenityx xar'kovchan [100 well-known citizens of Kharkov]. Kharkov: FOLIO.

Kuznets Simon S. (1921). Denezhnaya zarabotnaya plata rabochix i sluzhashhix fabrichnozavodskoj promyshlennosti g. Xar'kova v 1920 godu [Money wages of factory employees in Kharkov in 1920] // Materialy po statistike truda na Ukraine [Materials on labor statistics of Ukraine] / Pod red. zav. Otdelom statistiki I.N. Dubinskoj. Vyp. 2 [I.N. Dubinskaja, ed. $2^{\text {d }}$ issue]. Kharkov.

(1930). Secular movements in production and prices: their nature and their bearing upon cyclical fluctuations. Boston and New York.

(1946). National products since 1869. N.Y.

(1952). Long-term changes in the national income of the United States of America since 1890 // Income and wealth of the United States: trends and structure. Income and wealth series. Vol.2. Cambridge.

(1953). International differences in income levels: reflection on their causes // Economic change. New York.

(1954). Dolya lic s vysokim doxodom v nacional'nom doxode i sberezheniyax [Shares of upper income groups in income and savings] // Novye knigi za rubezhom po obshhestvennym naukam [New editions abroad on social sciences]. №2. Moscow.

(1955). Economic growth and income inequality // The American economic review. Vol.XLV. №1. 
(1956). Ekonomicheskoe razvitie Brazilii, Indii, Yaponii [Economic growth: Brazil, India, Japan] // Novye knigi za rubezhom po obshhestvennym naukam [New editions abroad on social sciences]. №13. Moscow.

(1958). Long swings in the growth of population and in related economic variables // Proceedings of the American philosophical society. Vol.102. №1: 25-52

(1959). Six lectures on economic growth. Glencoe, Illinois: Free Press.

(1961). Capital in the American economy: its formation and financing. Princeton.

(1963). Quantitative aspects of the economic growth of nations: VIII. Distribution of income by size // Economic development and cultural change. Vol.11. № 2. Part 2: 1-80. Kuznets S. (1965). Economic growth and structure: selected essays. N.Y.

(1966). Sovremennyj ekonomicheskij rost: norma, struktura i protyazhennost' [Modern economic growth: rate, structure and spread]. Moscow: Ekonomika.

(1968). Developed and underdeveloped countries: some problems of comparative analysis // Zeitschrift für die gesamte Staatswissenschaft. Bd. 124.

(1970). Demograficheskie aspekty sovremennogo ekonomicheskogo rosta [Demographic aspects of modern economic growth] // Naselenie i ekonomika. Novoe v zarubezhnoj demografii. Sb.3 [Population and economy. New in foreign demography. Vol.3] / A.G. Volkov, A.J. Kvascha, eds. Moscow: Statistika: 103-166.

(1972). Ekonomicheskij rost nacij. Sovokupnyj produkt i struktura proizvodstva [Economic growth of nations: total output and production structure] // Novye knigi za rubezhom po obshhestvennym naukam [New editions abroad on social sciences]. №7. Moscow.

(1973). Naselenie, kapital i rost. Sbornik ocherkov [Population, capital and growth: selected essays]. Moscow: Statistika.

(1974). Demographic aspects of the distribution of income among families: recent trends in the United States / Econometrics and economic theory: essays in honor of Jan Tinbergen. W. Sellekaerts, ed. London.

(1975). Population trends and modern economic growth: notes towards a historical perspective . Population debate: dimensions and perspectives. Papers of the World population conference. Bucharest, 1975. Vol.1 // Population studies. №57.

Kuznets S.S., E.D. Burdick, E.P. Hutchinson, D.T. Rowlands (1946). Population of Philadelphia and environs in 1950. Philadelphia: University of Pennsylvania Press.

Laureaty Nobelevskoj premii po ekonomike: v 3 t. [Nobel Prize Winners in Economics. In 3 vol.] (2007) / V.V.Okrepilov, ed.. T.1: 1969-1982 [Vol.1: 1969-1982]. Saint-Petersburg: Nauka

Lewis W.A. (1954). Economic development with unlimited supplies of labor // The Manchester school. Vol.22. Issue 2: 139-191.

Maddison A. (2004). Contours of the world economy and the art of macro-measurement 1500$2001 / /$ Ruggles lecture, IARIW $28^{\text {th }}$ General conference. August 2004. Cork, Ireland. P. 68.

Mirovaya ekonomicheskaya mysl'. Skvoz' prizmu vekov. V 5 t. [World economic thought: Through the prism of centuries. In 5 volumes] (2004) / Vsemirnoe priznanie: lekcii nobelevskix laureatov. T.V v 2 kn. Kn.1 [Worldwide recognition: lectures of Nobel prize. Vol.V. Issue 1] / G.G. Fetisov, ed. Moscow: Mysl'. 
Moskovkin V. M. (2002). Semyon Kuznets: ego professional'noe okruzhenie v Khar'kove i pervaya nauchnaya rabota [Simon Kuznets: his professional environment in Kharkov and the first scientific study] // Business inform. № 9-10.

(2005). Semyon Kuznets: zhiznedeyatel'nost' i ego vklad v mirovuyu nauku [Simon Kuznets: life activity and its contribution to world science] // Problemi nauki, osviti ta upravlinnya. Zbirnik naukovix prac. Vyp.VII [The problems of science, education and management. Collection of scientific papers. Vol.VII].

(2010). Neizvestnyj Semyon Kuznets: ucheba v Xar'kove [Unbeknown Simon Kuznets: studying in Kharkov] // Universitates: nauka i prosveshhenie [Universitates: Science and Education]. №1.

Moskovkin V.M., D. Yu. Michailichenko (2012). Vstuplenie. Sajmon Kuznec i Xar'kovskaya vysshaya ekonomicheskaya shkola nachala XX st. [Introduction. Simon Kuznets, and the Kharkov Higher School of Economics at the beginning of the XX century] // Kuznets S. Ekonomicheskaya sistema d-ra Shumpetera, izlagaemaya i kritikuemaya; Perlman M. Dve fazy zainteresovannosti Kuzneca Shumpeterom [Kuznets S. Comment on the economic system of Dr. Schumpeter; Perlman Mark. Two periods of Kuznets' interest to the work of Schumpeter] / V.M. Moskovkin, D. Yu. Michailichenko, comp., V.S. Ponomarenko, ed. Kharkov: ID «INZhEK».

Nobel lectures. Economics 1969-1980 (1992) / A. Lindbeck, ed. Singapore: World scientific publishing Co.

Nobelevskie laureaty po ekonomike: vzglyad iz Rossii [Nobel prize winners of economic: a view from Russia] (2003) Y.V. Jakovets, ed. Moscow: "Gumanistika".

Nobelevskie laureaty XX veka. Ekonomika [Nobel prize winners of the XX century. Economics] (2001). Enciklopedicheskij slovar' [Encyclopedic Dictionary]. Moscow: ROSSPEN.

Reviews of books (1965) // The Journal of Economic History. Vol.25. Issue 03 (Sept).

Schultz T.W. (1961). Investment in human capital // American Economic Review. Vol.52. №1: $1-17$.

System of National Accounts 2008 (2009). European Commission, International Monetary Fund, Organisation for Economic Co-operation and Development, United Nations, World Bank.

Vernadsky V.I. (1977). Razmyshleniya naturalista. Kniga 2. Nauchnaya mysl' kak planetnoe yavlenie [Reflections of natural philosopher. Vol. 2. Scientific thought as a planetary phenomenon]. Moscow: Nauka. 